\title{
Simplified method for Ocular Rehabilitation: - A Case Report
}

\author{
Dr. Hardik K Ram ${ }^{1}$, Dr. Rupal J Shah ${ }^{2}$ \\ ${ }^{1}$ PG student, Department of Prosthodontics, Govt. Dental College, Ahmedabad, India \\ ${ }^{2}$ MDS, Head of Department, Department of prosthodontics, Govt. Dental College, Ahmedabad, India
}

\begin{abstract}
The eye is a vital organ and an important component of facial expression. Several ocular and orbital disorders require surgical intervention that may result in ocular defects. Loss of an eye has a crippling effect on the psychology of the patient. Enucleation of the eye is therefore normally followed by fabrication of an ocular prosthesis to improve esthetics. The primary purpose of an ocular prosthesis is to maintain the volume of eye socket and create the illusion of a healthy eye and surrounding tissue. A custom ocular prosthesis is a good option when reconstruction by plastic surgery or the use of Osseo-integrated implants is not possible or not desired. Prosthetic rehabilitation of a patient with missing eye with custom made ocular prosthesis was described.
\end{abstract}

Keywords: enucleation, implant, iris, ocular, sclera

\section{Introduction}

Eye is a vital organ not only in terms of vision but also being an important component of the facial expression. Removal of this organ may be indicated in cases of a congenital abnormality; severe trauma; or disease such as an infection, a tumor or malignancy either by evisceration (where the contents of the globe are removed leaving the sclera intact), enucleation (most common, where the entire eyeball is removed after severing the muscles and the optic nerve) or exenteration (where the entire contents of the orbit including the eyelids and the surrounding tissues are removed).[1,2]

Frequently, an implant is placed in the tissue bed to facilitate the construction of an ocular prosthesis. However, apart from its cost principal disadvantage associated with ocular implants is the erosion of the overlying tissue, resulting in the exposure of the implant or contamination of the implants at the time of insertion.[3]

An ocular prosthesis can be either readymade (stock) or custom-made. Stock prosthesis comes in standard sizes, shapes, and colors. They can be used for interim or postoperative purposes.[1,4,5] Custom eyes have several advantages including better mobility, even distribution of pressure due to equal movement thereby reducing the incidence of ulceration, improved fit, comfort, and adaptation, improved facial contours, and enhanced gained from the control over the size of the iris,pupil and color of the iris, sclera.This case report describes a simplified method for the construction of ocular prosthesis.

\section{Case Report}

A 58-year-old male patient reported to Department of Prosthodontics GDC\&H Ahmedabad with chief complain of difficulty in eating. On examination patient was completely edentulous. He had a history of trauma at the age of 52, and the eye was enucleated and a stock prosthesis was given. On examination, the tissue bed was irritated due to ill-fitting prosthesis. So, the patient was advised to discontinue wearing of the prosthesis. After a week, the patient was evaluated for the relationship of palpebral fissure in an open and closed condition, the muscle control of the palpebrae, and the internal anatomy of the socket in resting and in full excursion[Fig:-1]. There was adequate depth between the fornices, which could be utilized for better retention of the prosthesis. The patient was given an option of an implant-retained ocular prosthesis but the patient was not ready to take up the surgery due to economic reasons. So, it was decided to replace the missing eye with a custom-made ocular prosthesis.Entire procedure was explained to the patient and his consent was obtained. 


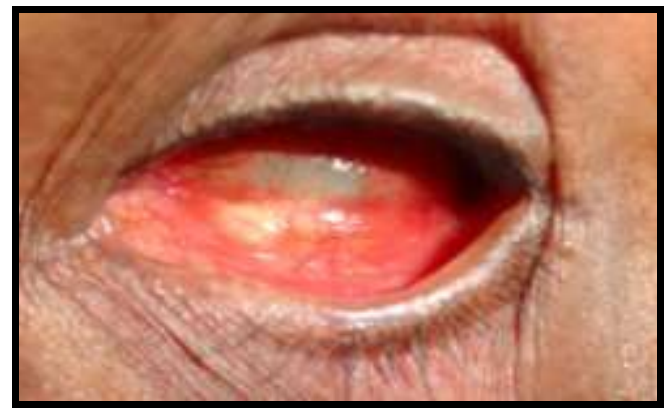

Fig:- 1 examination of the socket

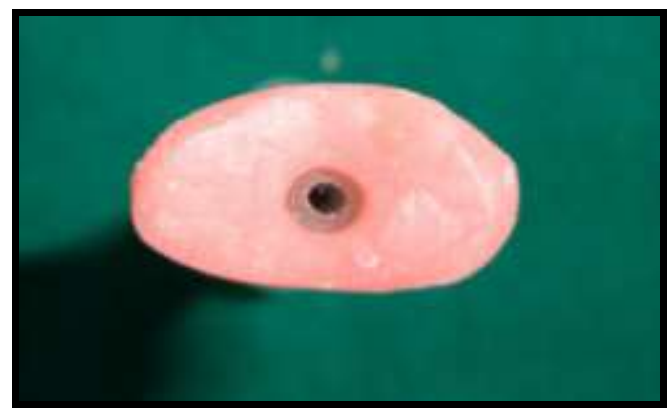

Fig:-2 autopolymerising resin tray

\subsection{Impression procedure[3,6,7]}

An ophthalmic topical anesthesia was given to increase the comfort of the patient while making the impression. External tray technique ${ }^{6}$ was used with light body wash impression for making the impression of the socket. An impression tray was fabricated from the autopolymerising acrylic resin[Fig:- 2]. The approximate pupil location on the resin tray was perforated to a 3 to 4-mm diameter hole. 5-ml plastic syringe (Unolok; Hindustan Syringes and Medical Devices Ltd., Faridabad, Haryana, India) was used for supporting the tray and to carry the impression material. Sides of the tip were roughened and wedged into the pupil perforation hole and sealed from external surface with autopolymerising acrylic resin[Fig:-3]. Addition silicon light bodied impression material was mixed homogenously and injected into the socket through injection. The patient was asked to move his normal eye in all directions to allow the material to flow into all areas of the enucleated socket, as well as onto the tray's outer surface to record lid movements. The patient was seated erect, requested to stare at a distant spot, and instructed to hold his gaze in a straightforward position with eyes open while the impression was being made.

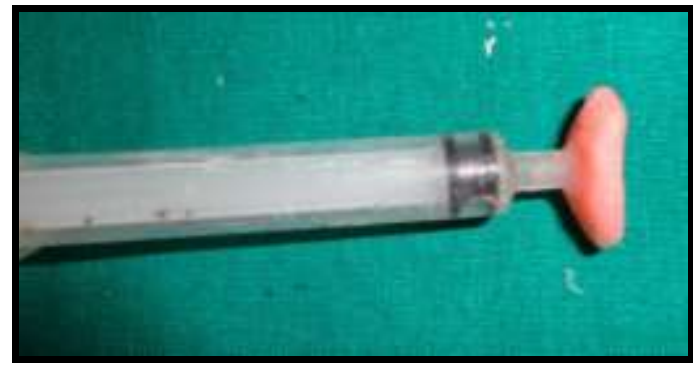

Fig:-3impression tray with syringe

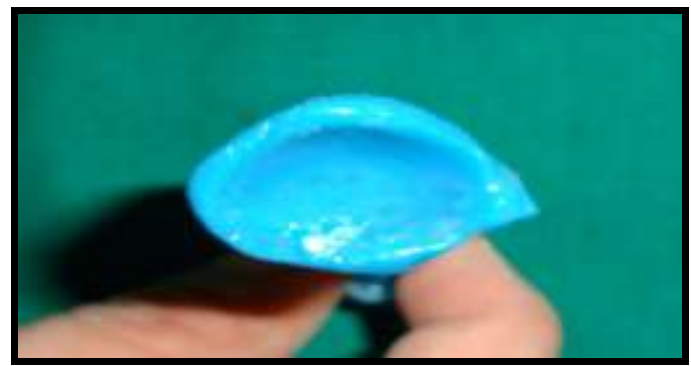

fig:-4 final impression

\subsection{Pouring of the cast}

After the material was set, it was carefully removed from the socket. The impression was checked to ensure that all the surfaces were recorded correctly [Fig:-4]. A two-piece Type IV dental stone cast (Kalrock; Kalabhai Dental, India) was poured to immerse the lower part of the impression. After the stone had set, the separating medium was applied on the surface. A second layer was then poured with type III dental stone. Markings were made on all four sides of the cast for proper reorientation.

\subsection{Fabrication and fitting of the sclera wax pattern}

The wax pattern was fabricated by pouring the molten wax into the cast. The wax was properly contoured and carved to give it a simulation of the lost eye. Try-in of the wax pattern was done. The wax pattern was checked for the size, support from tissue, simulation of eye movement, and eyelid coverage [Fig:- 5].

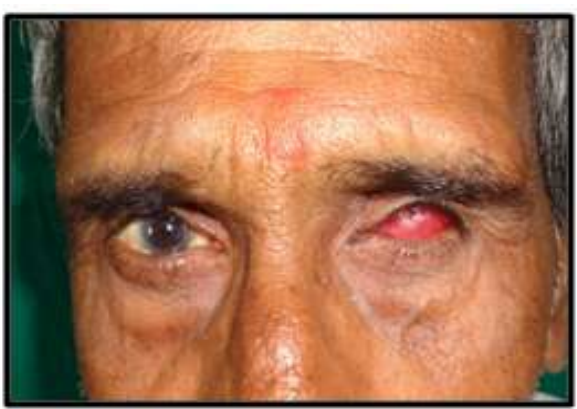

fig:-5 try-in of wax pattern

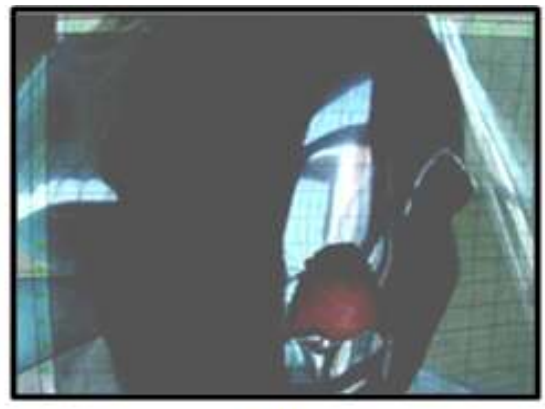

fig:- 6 milimeter grid placed on patients face 


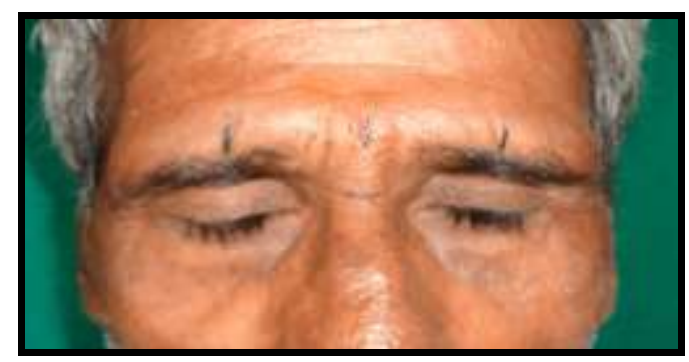

Fig-7 markings transfer

\subsection{Position of the iris-lens assembly on the scleral wax pattern}

The position of the iris was located with the help of a millimeter grid placed on the patient's face[Fig:-6]. The patient was instructed to fix the gaze of the natural eye on an object at least $3 \mathrm{ft}$ in front and at eye level. The position of the iris-pupil area of the natural eye in relation to the inner and outer canthus and upper and lower lids was marked on the grid. The same markings were transferred on the defect side [Fig:- 7]. Stock eye was selected with iris closely matching to patient's natural eye. That iris portion of the stock eye was carefully removed from scleral shell and fixed on the wax patttern according to the transferred markings and again try- in done[Fig:$8,9]$

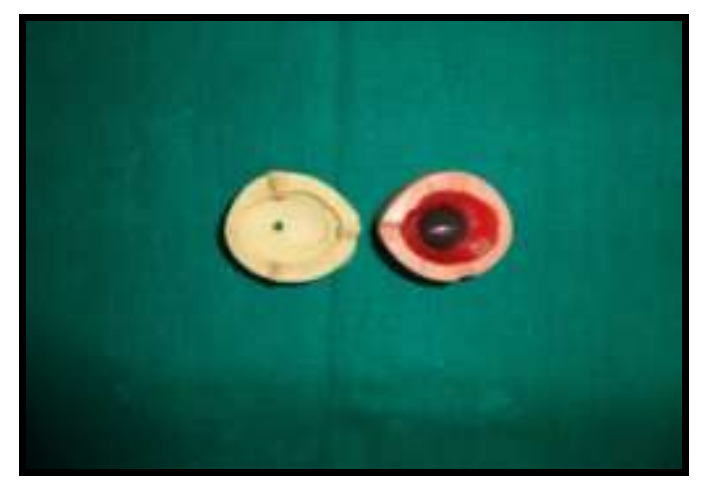

Fig:-8 iris of stock eye placed on scleral wax pattern

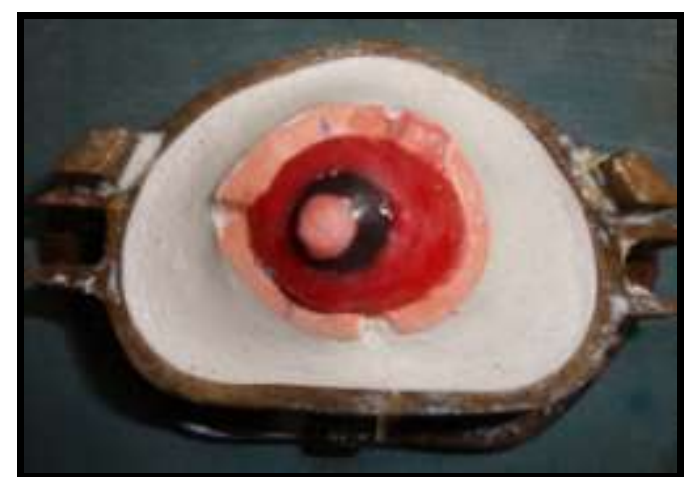

Fig:- 10 flasking of the wax pattern

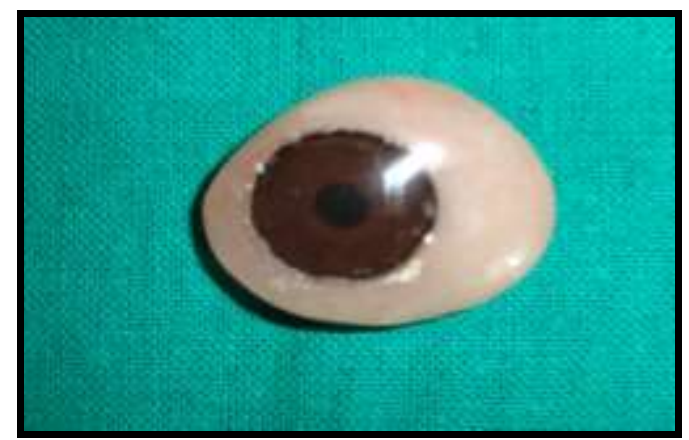

Fig:12 final prosthesis

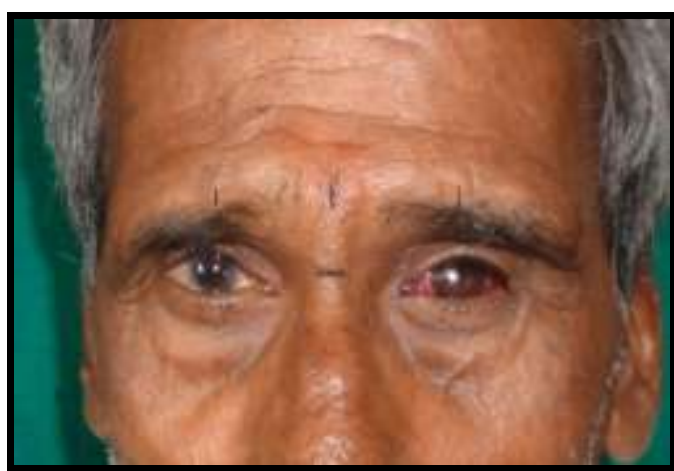

Fig:-9 try-in of the scleral wax pattern with iris

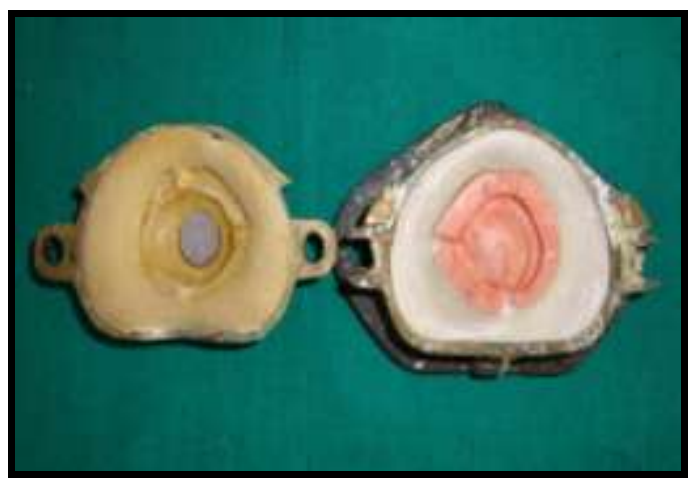

Fig:-11 dewaxing

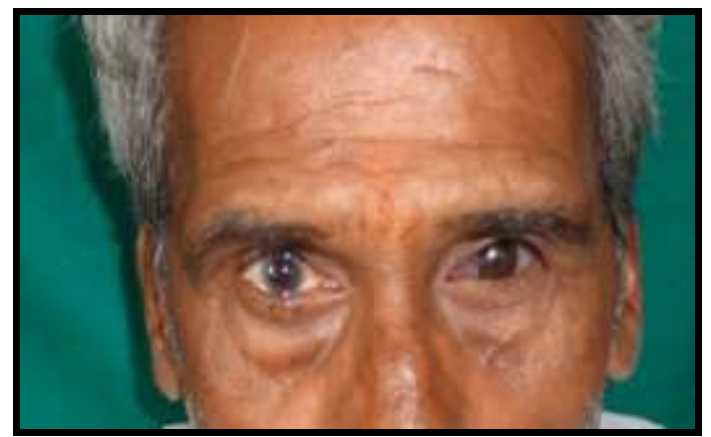

Fig:-13 satisfied patient 
The adjusted and modified stock eye-wax pattern combination was invested, flasked and de-waxing was done. Flasking was done taking care that the iris was secured to one counter of the flask and remaining part in the other portion of the flask[Fig:- 10,11]. Packing was done with the selected heat cure tooth colored acrylic. Red silk fibers to mimic veins were placed in the dough of the determined acrylic shade. A long curing cycle $\left(9 \mathrm{~h}\right.$ at $\left.165^{\circ} \mathrm{F}\right)$ was carried out for acrylization. The stalk of the ocular button, flash, and irregularities were removed from the surface. The prosthesis was finished and polished with the flour of pumice (Whip Mix Corporation, USA)[Fig:-12]. The properly finished and polished prosthesis was inserted in the socket after being disinfected and lubricated with an ophthalmic lubricant (Ecotears, Intas Pharmaceuticals Ltd, Ahmedabad, India) to maintain a tear film over the prosthesis and to improve eye movements. Minor adjustments were made at the time of delivery as per the patient's comfort and esthetics. Necessary instructions for cleaning, placement and removal of the prosthesis were given and the need for regular recall appointments was emphasized.[8]

\section{Discussion}

Except for ocular implants two other options are available for artificial eye prosthesis, one is a pre-fabricated ocular prosthesis and the other is custom-made. Pre-fabricated prosthesis carries potential disadvantages of poor fit (which endangers the eye to granuloma formation), poor esthetics and poor eye movements.[8] According to Beumer et al.,[3] intimate contact between the ocular prosthesis and the tissue bed is needed to distribute even pressure, so a prefabricated prosthesis should be avoided. Moreover, the voids in the prefabricated prosthesis collect mucus and debris, which can irritate mucosa and act as a potential source of infection, which are minimized in custom-made prosthesis.[8,9]

Custom-made prosthetic eye fabrication involves complex painting procedures in various stages that are quite difficult and based purely on painting skills of the operator.[10] The technique to fabricate ocular prosthesis in these case reports, modifies a pre-fabricated eye prosthesis to a custom-made fit and esthetics. This helped us to overcome the disadvantages of poor fit, esthetics and movement of a prefabricated prosthesis and complex painting procedure and technique involved in making a custom-made ocular prosthesis.

This technique would also be relatively easy to perform,along with saving on laboratory time. The close adaptation of the custom-made ocular prosthesis to the tissue bed provides maximum comfort and restores full physiologic function to the accessory organs of the eye. Voids that collect mucus and debris, which can irritate the mucosa and act as a potential source of infection may also be minimized.[11]

Limitations of the technique are that the clinician is dependent on the availability of a prefabricated eye with properly matching iris. Also, the long-term color stability of the heat-cured acrylic and the strength of its union with the stock eye will have to be closely evaluated.

\section{Conclusion}

A technique for fabrication of a custom-made ocular prosthesis has been described. This technique also permits the finished prosthesis to generate an equal distribution of pressure and intimate adaptation to the tissue bed. A properly fabricated custom-made prosthesis enhances the patient's comfort and confidence by increased adaptiveness and natural appearance, and also maintains its orientation when the patient performs various eye movements. The optimum cosmetic and functional results of a custom-made ocular prosthesis enhance the patient's rehabilitation to a normal lifestyle.

\section{References}

[1] Goel BS, Kumar D. Evaluation of ocular prosthesis. J All India Ophthalmol Soc 1969;17:266-9

[2] Nath K, Gogi R. The orbit. Indian J Ophthalmol 1976;24:1-14.

[3] Beumer J, Zlotolow I. Restoration of facial defects. In: Beumer J, editor. maxillofacial rehabilitation - prosthodontic and surgical considerations 1st ed. St. Louis: C. V. Mosby publishers; 1996. p. 350-64.

[4] El-Dakkak M. Problem solving technique in ocular prosthetic reconstruction. Saudi Dent J 1990;2:7-10.

[5] Smith RM. Relining an Ocular Prosthesis: A Case Report. J Prosthodont 1995;4:160-3.

[6] Mathews MF, Smith RM, Sutton AJ, Hudson R. The ocular impression: A review of the literature and presentation of an alternate technique. J Prosthodont 2000;9:210-21.

[7] Shenoy KK, Nag VP. Ocular impressions: An overview. J Indian Prosthodont Soc 2007;7:5-7

[8] Cain JR. Custom ocular prosthesis. J Prosthet Dent 1982;48:690-4.

[9] Grisius MM, Robert L. Treatment of lagophthalmos of the eye witha custom prosthesis. J Prosthet Dent 1993;70:333-5.

[10] Allen L, Webster HE. Modified impression method of artificial eye fitting. Am J Ophthalmol 1969;67:189-218.

[11] Murphy PJ, Schlossberg L. Eye replacement by acrylic maxillofacial prosthesis. Naval Med Bull 1944;43:1085. 